Revista de la red interuniversitaria de estudios sobre las literaturas rioplatenses contemporáneas en Francia

17 | 2017

Hermetismo programático en la literatura rioplatense contemporánea (de 1980 a nuestros días)

\title{
Decir lo indecible. Violencia política y hermetismo en la escritura de Luis Gusmán
}

Andrea Cobas Carral

\section{OpenEdition}

1 Journals

Electronic version

URL: http://journals.openedition.org/lirico/3946

DOI: 10.4000/lirico.3946

ISSN: 2262-8339

Publisher

Réseau interuniversitaire d'étude des littératures contemporaines du Río de la Plata

Electronic reference

Andrea Cobas Carral, « Decir lo indecible. Violencia política y hermetismo en la escritura de Luis Gusmán », Cuadernos LIRICO [En línea], 17 | 2017, Puesto en línea el 06 diciembre 2017, consultado el 06 mayo 2019. URL : http://journals.openedition.org/lirico/3946 ; DOI : 10.4000/lirico.3946

This text was automatically generated on 6 May 2019.

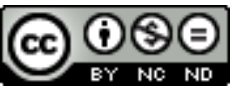

Cuadernos LIRICO está distribuido bajo una Licencia Creative Commons Atribución-NoComercialSinDerivar 4.0 Internacional. 


\title{
Decir lo indecible. Violencia política y hermetismo en la escritura de Luis Gusmán
}

\author{
Andrea Cobas Carral
}

Esos cuerpos encontraban la muerte por agua sumidos en el sueño. Unos ojos despertaron y lo miraron un instante. Se abrieron para condenarlo a vagar como sombra.

Luis Gusmán, En el corazón de junio. ${ }^{1}$

1 ¿A través de qué procedimientos la escritura puede tramar la violencia política en el momento exacto en el que esa violencia se ejerce sobre los cuerpos y sobre las palabras? ¿Cómo es posible adentrarse en la experiencia de la aniquilación y la censura para mostrarla en el revés del texto? ¿Cómo componer una escritura que funde sentidos capaces de decir lo que parece indecible en un contexto atravesado por la represión, la desaparición y la muerte? La novela En el corazón de junio de Luis Gusmán -publicada originalmente en 1983, el año final de la última dictadura cívico-militar argentina (1976-1983)- constituye un objeto de análisis pertinente para pensar algunas de esas cuestiones.

2 En ese sentido proponemos un abordaje de En el corazón de junio enmarcando su análisis en dos momentos de la labor literaria de Gusmán que se recortan con claridad. Por un lado, sus primeros textos están marcados por su pertenencia al núcleo de escritores que integran las revistas Literal (1973-1977) y Sitio (1981-1987), publicaciones en las que -como veremos- se manifiestan concepciones de la literatura que, con modulaciones, pueden ser reunidas a partir de su oposición al realismo. Un recorrido por los postulados estéticos de Literal y Sitio puede ser productivo en tanto es, justamente en esos años, cuando Gusmán publica sus primeras ficciones y escribe algunos fragmentos que integran después la primera edición de En el corazón de junio. Por otro lado, hacia mediados de los 80, Gusmán repiensa aquellos postulados y opera sobre sus textos un proceso de revisión que materializa su paulatino alejamiento de las concepciones estéticas que primaron durante su etapa anterior, proceso que tiene su punto culminante en la publicación en 1995 de la novela Villa y en la reescritura en 1999 de En el corazón de junio. Es decir, para figurar la 
violencia política Gusmán hace un viraje desde una estética que apela a la construcción de una prosa que desestabiliza los rasgos prototípicos del relato tradicional de corte realista hacia un tipo de escritura que indaga la referencialidad a través de formas de representación más cercanas al realismo. Esa transformación debe ser pensada atendiendo tres ejes que permiten historizar su práctica de escritura y que vuelven más evidentes, por contraste, los rasgos de la prosa de En el corazón de junio: en primer lugar, la pertenencia de Gusmán a un colectivo que, en los años previos al golpe de Estado, discute la relación arte/política; en segundo lugar, la necesidad de proponer un tipo de figuración literaria capaz de denunciar la violencia de Estado, pero que, al hacerlo en el contexto mismo de la dictadura, obliga a un tipo de escritura que -como veremos- desafía la inteligibilidad; y por último, un cambio de época que es también para Gusmán la profundización de otros modos de concebir la labor literaria y la función de la literatura en el contexto de la democracia. Opciones estéticas que no pueden desligarse del contexto político y cultural en el que se discuten los modos de posicionamiento del escritor ante la violencia política y los instrumentos más adecuados para figurarla en el relato.

Entonces la focalización en las dos versiones de En el corazón de junio permite, justamente, advertir por contraste procedimientos para figurar la violencia de Estado en la primera edición de la novela, texto especialmente relevante en tanto logra sobreponerse a la censura impuesta por el régimen dictatorial y llenar de sentido desde la figuración literaria el silencio social en torno de la desaparición: elipsis, alusiones y símbolos son algunas de las figuras retóricas que funcionan en distintos planos de la novela en su primera edición y que son resemantizadas en la segunda. En este sentido, es operativo retomar para el estudio de la primera etapa en la escritura de Gusmán -y en especial para la edición del 83 de En el corazón de junio- la noción de hermetismo "programático " (Saer, 151) en tanto partimos de la idea de que el texto pone como rasgo medular de su configuración estética el problema de la construcción de sentido: el hermetismo aparece así como una problemática poética que la ficción construye como tema y que permite, por extensión, significar la violencia y decir aquello que no podría ser dicho de otro modo. La «desviación » de sentido implícita en el hermetismo " programático » es una estrategia que propone una ficción bifurcada entre una superficie oscurecida y un sentido refractario que, poco a poco, se devela ante el lector capaz de bucear en esa oscuridad (Saer, 151). En consonancia con esa idea -y justamente a través de una prosa que sumerge al lector en un ejercicio de desciframiento-, Gusmán propone una ficción organizada por estrategias que exhiben y problematizan el acto mismo de interpretar y que se suman a las figuras retóricas señaladas: la lectura crítica, la adivinación y la traducción aparecen como zonas tematizadas en la novela y entre cuyos intersticios se entrevé la violencia de Estado.

\section{I- De El frasquito a En el corazón de junio: una poética del desciframiento}

La literatura es posible porque la realidad es imposible.

Literal, $n^{\circ} 1 .^{2}$

Los debates sobre los grados de subordinación de la literatura a la política se replican, una y otra vez, en diversas coordenadas nacionales e históricas y muestran posicionamientos diversos respecto de la tensión arte/política. En los 70 las limitaciones del proyecto de las vanguardias históricas aparecen en el panorama de una "generación" de jóvenes 
latinoamericanos que -post revolución cubana- se sienten otra vez ante «el dilema »para decirlo con Claudia Gilman (2003)- de un compromiso siempre problemático del escritor con los procesos revolucionarios: para muchos de los jóvenes que escriben en esos años, la revolución muestra la unidad profunda latinoamericana que debe conseguirse con el fusil, pero que debe hacerse evidente también en un tipo de relato capaz de generar conciencia y que se inserte en la larga tradición que en Latinoamérica tiene el realismo.

5 Si en 1970 el proyecto de expansión del proceso revolucionario a toda América Latina es, cuanto menos, "pensable », hacia mediados de la década la posibilidad de la derrota no puede ya ignorarse. ${ }^{3}$ Los recientes golpes de Estado en Uruguay, Chile y Argentina -si nos focalizamos sólo en el sur del Cono sur- marcan un presente que excluye la ingenuidad y el voluntarismo. Con ese contexto continental como marco, los 70 constituyen en Argentina un período de alta conflictividad política. Entre la tercera presidencia de Juan Domingo Perón (1973) y el golpe de Estado que pone fin al gobierno encabezado por su viuda median casi tres años en los que fracciones de las militancias tanto peronistas como marxistas eligen la lucha armada y la represión parapolicial legitimada desde el Estado se ejerce sobre ellas en una trama de creciente violencia que opera también hacia dentro del campo intelectual y que se manifiesta en adhesiones, realineamientos y disputas sobre el proceso político en curso y sobre las funciones adecuadas para la literatura en ese proceso. ${ }^{4}$ El golpe cívico-militar del 24 de marzo de 1976 inicia en Argentina un ciclo de inusitada represión y violencia: censura, exilio y desaparición son la síntesis del impacto que la última dictadura supuso en todos los órdenes. Es justamente en esos años que Luis Gusmán inicia su carrera literaria.

6 La publicación a principios del 73 de la novela breve El frasquito, de Gusmán se suma a Nanina (1968), de Germán García y El fiord (1969), de Osvaldo Lamborghini, textos que retrospectivamente y en un gesto que casi replica la indiferenciación autoral que es la marca de Literal- son leídos por la crítica como una suerte de « trilogía » determinada, por un lado, por los procedimientos de renovación y experimentación narrativa que materializan y, por otro, a causa de la cercanía de sus autores quienes, en noviembre del 73, convergen en la creación de la revista Literal, desde cuyas páginas delinean un programa estético que pone en circulación saberes ausentes en otras publicaciones relevantes del período como Los libros o Crisis, orientadas hacia una paulatina latinoamericanización y atentas a los debates asociados con esa adscripción. ${ }^{5}$ En su estudio Literal. La vanguardia intrigante, Ariel Idez analiza los textos programáticos en los que la revista recorta dos antagonistas precisos y bien visibles en su contexto de enunciación: el realismo y el populismo. Literal debate la autonomía de la literatura y al hacerlo reivindica la escritura como práctica simbólica superadora de una coyuntura que reclama un tipo de creación que sea acción militante. Idez sintetiza esa apuesta afirmando que Literal propone "en lugar de una literatura política, una política de la literatura " (65). Como lo hace con sus antagonistas, Literal también selecciona una tradición que le sirve como anclaje en el marco de su ruptura radical con las líneas hegemónicas del campo cultural. «Macedonio, Girondo, Borges » (5) sostiene Libertella citando a Osvaldo Lamborghini. La vanguardia, sí, pero además, la puesta en el centro de una reflexión sobre el lenguaje en su matriz creadora: el cruce entre una teoría que sustenta la ficción y una ficcionalidad que, en un movimiento autorrecursivo, se instala como su propio centro en tanto única clave posible para descifrar sus sentidos. Juego del lenguaje y saber sobre la lengua, pero además una apuesta estética con implicancias profundamente políticas. 
Literal aboga entonces por una literatura capaz de romper con la «pre-potencia del referente » (24) y de sustraerse de la función instrumental de la palabra negándose a hacer de la denuncia un hecho estético. Una literatura que se enuncia en su propia práctica, pero que « sin alucinar la vida » (136) puede narrarla.

En esa línea, Luis Gusmán compone El frasquito a partir de esos principios estéticos y logra un texto que puede ser pensado bajo los términos en que describimos el hermetismo " programático ", es decir, en tanto puesta en tensión entre una "superficie oscurecida " y un " sentido refractario »: la erosión de las categorías de tiempo y espacio, la fragmentariedad, la presencia de lo alucinatorio y lo onírico, la ruptura con cualquier tipo de referencialidad, las múltiples enumeraciones caóticas y el borramiento de las cadenas causales son algunos de los procedimientos de los que deriva ese sentido que se resiste a cualquier clausura unívoca. Es así que lo hermético de El frasquito opera en dos direcciones: hacia dentro de la estructura textual tramado en la opacidad de un lenguaje que erosiona los procedimientos de armado del relato tradicional y hacia afuera apuntando a las expectativas estándar de lectura de un público al que el texto empuja más allá de los límites convencionales de lo decodificable. A contrapelo de lo que señalan algunas críticas, no se trata tan solo de pensar los grados de "sorpresa " que un lector adiestrado en el abordaje de textos de ruptura puede tener luego de la lectura de $\mathrm{El}$ frasquito o el rechazo que pudieran sentir aquellos lectores « conservadores » a ultranza ante un texto que se les escapa ni se trata tampoco de concebir el paratexto como sagrada clave de lectura que determina el sentido de la ficción y moldea una experiencia de la que el lector nunca se aparta. Mejor pensar que lo " sorpresivo ", en tal caso, no se sujeta sólo al quiebre de una linealidad temporal o a la labilidad de las categorías de la novela tradicional o a un lúdico desafío o la puesta en texto de tal o cual teoría sino más bien que se liga con la manera en que esos procedimientos que orillan el sentido hacen brotar de su estructura un orden opresivo en una figuración que obtura todas las salidas: más que por sus « efectos de lectura » siempre difíciles de medir, El frasquito puede ser leída en su capacidad para referir la violencia social apartándose de los modelos hegemónicos en su contexto de publicación.

El frasquito, después de todo, narra el fatal círculo de una vida: el narrador completa una trayectoria vital de niño a adulto hasta transformarse -asumidos todos los costos, frustradas todas las esperanzas- en ese « otro » que es su padre: novela de aprendizaje en la que sólo se aprende que no hay escapatoria. La leche como un significante que recorre el texto aúna múltiples significados en el relato, líquido seminal y alimento, se filia con el par paternidad/maternidad y se proyecta en la dicotomía entre prácticas sexuales "productivas » e «improductivas »: mientras el padre Montana solo piensa en «hacer uso » con la Madrecita, el hijo-narrador se obstina en la anticoncepción, la masturbación y el sexo anal. De todos modos, el frasquito roto con el semen improductivo del padre es la contrapartida del fracaso del hijo en sus prácticas profilácticas cuando se sabe para siempre un padre tan malo como lo fue el suyo propio. El «relato fuera de la ley »-como lo califica Ricardo Piglia en su célebre prólogo a la primera edición- termina por encuadrarse en una legalidad que clava al narrador en el marco de un espacio marginal del que no puede salir, espacio signado por la violencia, la simulación y el ensueño en el que ocurre su inevitable metamorfosis, dando inicio así a un nuevo ciclo, reproducción mediante. El fragmento en el que el narrador y el «paraguayo » caen a un pozo ciego mientras realizan entre sí ciertas prácticas sexuales a pasos de sus mujeres embarazadas religa diversas líneas de sentido del relato y fija el alcance de su cierre: « [la Madrecita] 
nos tira una soga, una sola soga, ya no tenemos más ganas de seguir luchando por la posesión de nada, la soga queda corta, le añade otro pedazo y tampoco sirve, no alcanza, queda corta, corta para siempre » (75). Escritura la de El frasquito que pone en texto una ferocidad sobre los cuerpos que muestra el armazón de las relaciones sociales y políticas e invierte su apuesta estética al darle -por exceso- un tiro de gracia al más crudo naturalismo. En este sentido -y para precisar aún más la síntesis formulada por Idez-, la narrativa de los autores ligados con Literal es política aunque no lo sea en los términos que exige cierta concepción del realismo. Parte de la narrativa de Gusmán más que sólo « ilegible » en la porción de sentido que trama su lenguaje, es perturbadora en tanto el lector, una vez captada la referencialidad, decodifica la matriz de una violencia que no se resuelve en ningún plano. Una literatura entonces que «sin alucinar la vida » puede narrarla.

9 Si El frasquito es la inauguración de una poética en la que lo hermético reposa en un programa estético que opone a los postulados del realismo ruptura, experimentación y una redefinición del valor de la palabra, la represión que se intensifica con la dictadura es una circunstancia que obliga a una revisión de ese paradigma poético. Junto con Nadie nada nunca (1980) de Juan José Saer y Respiración artificial (1980) de Ricardo Piglia, En el corazón de junio de Gusmán constituye el núcleo central de una narrativa escrita en Argentina durante la dictadura que exterioriza las huellas de la violencia sobre los cuerpos, las identidades y los imaginarios a través de estrategias que incluyen la fragmentación discursiva, la construcción de alegorías, la recuperación de la tradición literaria argentina y la puesta en texto de diversas operaciones de intertextualidad. ${ }^{6} \mathrm{Si}$ en El frasquito el hermetismo de la prosa obedece a una disputa hacia dentro del campo literario, el hermetismo de En el corazón de junio sirve como coartada para eludir la censura y como medio para narrar una violencia que es, parcialmente, de otro signo.

\section{II- En El corazón de junio: palabras para decir lo indecible}

El inscriptor atiende el sentido que flota -como la mosca- sabiendo que no podrá

cazarlo en el aire.

Literal № 1: una intriga (25).

10 En su ensayo Cómo sucedieron estas cosas, José Emilio Burucúa y Nicolás Kwiatkowski se interrogan acerca de la noción de irrepresentabilidad de las masacres históricas a través del arte. En su reflexión concluyen en que lo inefable surge como impresión en tanto los episodios de violencia histórica funcionan como una suerte de quiebre radical de la causalidad que sustenta un determinado ordenamiento social. En ese marco, la literatura busca encontrar las palabras para decir eso que se resiste a ser dicho porque transgrede el orden de lo pensable en un momento dado. En el corazón de junio -publicada hacia el final de la dictadura, pero escrita durante los años anteriores- ${ }^{7}$ apuesta al hermetismo como única condición de posibilidad de la ficción, como único modo eficaz de rozar a través del lenguaje la violencia de su presente.

11 En una crítica pionera sobre la novela de Gusmán, Daniel Balderston advierte la presencia de dos clases de silencios que denomina « lo borrado » $\mathrm{y}$ « lo ilegible». La diferencia se relaciona con lo que puede o no hacer el lector con esos silencios que el texto presenta como enigmas: lo borrado, según Balderston, podría recuperarse desde una lectura hábil para encontrar los « significados latentes », mientras que lo ilegible -que para Balderston 
se da en el nivel de articulación entre los segmentos- impide que el texto sea leído como una narración y, por lo tanto, eso "borroso sugiere la imposibilidad de conocer la verdad» (119). ${ }^{8}$ La lectura de Balderston participa de las discusiones coyunturales que se dan en los primeros años del retorno de la democracia acerca de la literatura escrita en Argentina y en el exilio durante la dictadura. En ese sentido, el énfasis en la ausencia de una «verdad» que se liga con lo que la escritura tiene de hermético sugiere por extensión el «fracaso » de la novela para dar cuenta de la violencia política en los términos adecuados. La supuesta « verdad» escondida en los silencios que atraviesan el texto sólo podría surgir si se volvieran evidentes las claves para llenar de sentido los enigmas planteados que no se resuelven, la «verdad» se volvería evidente si, una vez atravesada la experiencia perturbadora de lectura, el lector pudiera establecer algo así como un principio de "orden" en el caos de los fragmentos, una suerte de reordenamiento de lo dicho que -una vez descorrido el velo de lo "ilegible», una vez resueltos los enigmas- dejara aparecer esa « verdad» con cierta nitidez. Por el contrario, pareciera más bien que la potencia de En el corazón de junio para figurar la violencia -por lo menos en su primera edición- se trama en la presentación de figuras pareadas que se tensionan y se superponen: lo elidido y lo dicho, la inscripción y el borramiento, lo hermético y su interpretación sin terminar nunca de clausurar un sentido unívoco que pueda resolver esas tensiones implícitas en su disposición oximorónica.

12 En Literal № 1: una intriga -afiche con el que empapelan el microcentro porteño un mes antes del lanzamiento de la revista- sus creadores sostienen: «El texto se define en una ambigüedad que es condición de su legibilidad: si todo estuviese dicho en la superficie de cada palabra, no habría nada que leer en la relación que hay entre ellas » (135). En el corazón de junio recupera en parte ese principio y carga de sentido el intersticio entre los fragmentos que componen su trama. Pero no sólo aparece Literal y su concepción de la literatura como trasfondo de En el corazón de junio: cuando la novela se edita, la experiencia Literal -formalmente terminada en 1977- ya ha quedado atrás para Gusmán . En 1981, en el escaso margen que la dictadura deja para el ejercicio intelectual, Gusmán funda la revista $\mathrm{Sitio}^{10}$. En su primer número -además de «El hombre de los gansos »- se publica "Escribir entre líneas, un arte olvidado », de Leo Strauss. Precedido por una breve nota de Jorge Jinkins en la que afirma que «la política puede prohibirse, pero no censurarse » (8), el artículo de Strauss funciona como una sucinta teoría sobre la escritura bajo regímenes totalitarios:

La persecución no puede impedir el pensamiento independiente [...] no pude incluso impedir la expresión pública de la verdad heterodoxa [...] Puede incluso hacerla imprimir, en tanto sea capaz de escribir entre líneas [...] Utilizaría muchos términos técnicos, haría muchas citas y dedicaría una importancia indebida a detalles insignificantes; daría la impresión que olvido la guerra santa de la humanidad por las querellas mezquinas de los pedantes. Sólo al llegar al corazón de la argumentación escribiría tres o cuatro frases de ese estilo conciso y vivo que es apto para detener la atención de los hombres que aman pensar (9).

13 Lo que Strauss formula para el discurso de la historia puede extrapolarse para pensar los rasgos que convergen en la composición hermética que Gusmán construye en las páginas de En el corazón de junio. La novela pone en texto y tematiza la necesidad de volver, una y otra vez, sobre lo cifrado, sobre esa porción de sentido que debe ser develada, sobre aquello que está inscripto y que prevalece en su opacidad con un sentido menos inteligible que el de la letra, eso que debe ser leído entre líneas, interpretado, indagado en el revés de una escritura: «Leer -dice el narrador del primer y extenso capítulo de la 
novela- es como profanar un secreto " (100). La noción misma de desciframiento presupone la presencia de un sentido que, cuanto menos, puede ser aprehendido si se sabe leer entre líneas.

Por un lado, la inclusión en el plano ficcional de la lectura crítica como un ejercicio de interpretación le da unidad a la novela y la atraviesa de principio a fin. "Corazón sencillo » de Gustave Flaubert, Corazón débil de Fedor Dostoievski, El corazón de las tinieblas de Joseph Conrad, pero también Ulises y Finnegans Wake de James Joyce y « Los donguis » de Juan Rodolfo Wilcock son el centro de la figuración. En primer lugar, porque el narrador que intenta saber el origen del corazón que acaban de transplantarle se avoca a un trabajo obsesivo de lectura y desciframiento de esos textos intentando hallar en ellos la clave para entender el malestar de su presente y, en segundo lugar, porque la serie de referencias a Wilcock -escritor ítalo-argentino y traductor de Joyce hallado muerto de un infarto mientras leía un tratado sobre el corazón- le sirve a Gusmán para fundir los diversos planos de la novela a través de la noción de interpretación: el narrador que indaga en Wilcock que indaga en Joyce compone una búsqueda cuyo relato es, página tras página, cada vez más enmarañado y que termina por construir una ficción de sentidos tan dispersos y recursivos que hace casi imposible elegir siquiera una cita capaz de dar cuenta cabalmente de esa complejidad. Como veremos, es justamente en ese marco que Gusmán hace entrar en el texto la dimensión política a partir de la coincidencia entre el " bloomsday ", la fecha en que muere el hermano de Joyce y el bombardeo de 1955 a Plaza de Mayo. ${ }^{11}$ La literatura como un entramado de sentidos que exige un trabajo hermenéutico aparece así como objeto de indagación en diversos momentos de la novela y su especificidad, a la vez, se funde y constituye la trama de En el corazón de junio.

Por otro lado, hay una serie de capítulos dedicados a narrar "videncias» que se intercalan entre los capítulos en los que el ejercicio crítico es el eje. Esa segunda serie de fragmentos no estabiliza el sentido general sino que, por el contrario, suma otra articulación al trabajo de lectura que el texto exige aunque, a diferencia de los fragmentos que desarrollan una lectura crítica, esta vez la «interpretación » de las videncias y su enlace con el resto corre completamente por cuenta del lector. Como vasos comunicantes, las visiones enlazan de manera difusa los diversos planos de la narración y "median " entre ellos con su carga fantasmal que proyecta un matiz ominoso sobre el resto del relato.

Por último, también la traducción aparece en En el corazón de junio como una práctica que el texto aprovecha para poner en escena las dificultades implícitas en todo proceso de transposición: Joyce es Joyce, pero además es Borges traductor del Ulises, es Cabrera Infante traductor de Dublineses, es Wilcock traductor de Finnegans Wake. Es el texto y sus lecturas, el texto y sus traductores. Capa sobre capa, fragmento tras fragmento, la elipsis, la alusión y los símbolos que exigen ser descifrados, llenados de sentido y estabilizados aparecen como condición de posibilidad para el ejercicio interpretativo. Lo inscripto y su « sentido que flota » (Literal, 25) presuponen en la novela la necesidad de alguien que lea. El « decir entre líneas » sólo es eficaz si aparece en el plano de la figuración «el hombre de bien que desea pensar " (Sitio, 9). La inscripción habilita una interpretación que en En el corazón de junio adquiere la forma de la lectura crítica, de la adivinación, de la traducción: lo inscripto que debe ser descifrado en el texto desafía el hermetismo, la inscripción que presupone una mirada erosiona por definición el estatuto del secreto y, por extensión, se proyecta como gesto más allá de la ficción en su posibilidad de referir la violencia política. 
17 Fragmentos, lecturas y videncias están atravesados por la presencia de la muerte. Desde Flores que recibe un corazón que le prolonga la vida, pero lo lanza a esa búsqueda obsesiva por saber qué llevó a su donante al suicidio, hasta las múltiples referencias a animales desollados, carneados y putrefactos que aparecen en cada fragmento, lo ominoso se intensifica hasta llegar en el segundo capítulo a su articulación más concreta en relación con la violencia de Estado. "Darkness » juega con las alusiones al texto de Conrad, pero construye además un sentido subterráneo que -casi a la manera de Straussemerge en dos o tres momentos de ese y otros capítulos de manera precisa: cuerpos despedazados que son lanzados al río, cuerpos familiares desaparecidos, cuerpos que encuentran la muerte « sumidos en el sueño » (122), cuerpos « arrebatados por la peste metálica » (241). Carlos Gamerro en su «Introducción » a Ulises. Claves de lectura sostiene que la novela de Joyce es -además de una enciclopedia de artes, ciencias y técnicas literarias- una enciclopedia sobre el cuerpo humano que va construyendo parte por parte hasta presentar una unidad (25). En En el corazón de junio, Gusmán parece invertir ese gesto: en la novela nos encontramos confrontados, por el contrario, con la progresiva disolución de los cuerpos, con su borramiento, con su desaparición. En una lectura inaugural de la novela, Jorge Monteleone determina certeramente la "pasión » que domina la ficción y que marca su ritmo: « el miedo, nuestro miedo » (95).

Como dijimos, la fecha clave del 16 de junio, de algún modo, enlaza el plano de las referencias literarias con el plano de la historia argentina y se proyecta sobre el presente del relato trazando una línea de continuidad entre el intento de Golpe de Estado del 55 y el Golpe del 76. Las temporalidades se superponen en ese 16 de junio: el encuentro de James Joyce y su futura esposa Nora, el día en que «transcurre » el Ulises, el Bloomsday, la muerte de Stanislaus Joyce y el bombardeo a Plaza de Mayo. El «bloom » que cada tanto aparece en el relato deja de remitir al «estallido » de un florecimiento primaveral y se carga en su matiz de onomatopeya para recuperar aquel otro estallido sobre la Plaza, para recuperar aquellos otros cuerpos también despedazados por el accionar militar. De esos cuerpos desaparecidos por la violencia de Estado solo emergen trazas en una escritura que busca en los bordes de lo decible los modos de referir la desaparición y la muerte.

En 2002, Gusmán publica Ni muerto has perdido tu nombre, novela en la que narra la vida de un hijo de desaparecidos que busca su historia y, al hacerlo, vuelve a la antigua cantera donde sus padres fueron vistos por última vez antes de ser desaparecidos. Allí, el joven escribe con aerosol en las piedras los apellidos de sus padres en un gesto doblemente direccionado: hacia ellos, en tanto la escritura pública del nombre propio quiebra veinte años de borramiento y, hacia él mismo, por cuanto la recuperación de sus padres a través de la fijación que implica el hallazgo de la «tumba » funciona como anclaje de su propia biografía. En su ensayo Epitafios. El derecho a la muerte escrita (2005), Gusmán sostiene: « se trata de devolver un nombre y una historia, función que el epitafio condensa de manera ejemplar » (344). De algún modo, En el corazón de junio puede ser leída también como un doble epitafio, como una inscripción en la historia para aquellos muertos del 55 borrados de la versión oficial del pasado y para esos otros desaparecidos que son la continuidad en el presente de la escritura de aquella otra violencia.

\section{III- Palabras finales}

20 La publicación en 1995 de Villa marca el acercamiento de Gusmán a un tipo de representación cercana al realismo para la narración de la violencia política. Con algunas 
variaciones pronominales que generan cierta vacilación en la lectura, Villa cuenta algunos años en la vida de un médico colaboracionista que, sin demasiados cuestionamientos, asiste a un par de servicios del lopezrreguismo en sesiones de tortura. También en Villa la escritura ocupa un lugar aunque este sea opuesto al que posee en En el corazón de junio. Villa escribe en clave un registro de sus actividades ilegales como un resguardo para tiempos convulsos. La referencia a una escritura en su superficie hermética aparece como una más entre las malas elecciones que va haciendo Villa: es una escritura que no espera ningún lector que la descifre ni en ella se juega ningún saber crucial para el relato. Villa decide " traducir » su texto al español y el resultado es tan intrascendente como lo es el mismo Villa: el archivo - « el engendro » (208)- carece de valor documental y simbólico, no es más que la escritura de un desesperado que replica en sus trazos la confusión en la que se ve inmerso. Ya no hay lugar en la narrativa de Gusmán para referir la violencia a través de una escritura en clave criptográfica. Este movimiento que se inicia con Villa se consolida en 1999 en la reedición de En el corazón de junio.

21 En «La operación de la escritura. El concepto central de corrección », Noé Jitrik señala que toda reescritura implica una posibilidad de enmienda que se vuelve evidente a través de un acto de lectura: la corrección es un ejercicio personal de interpretación en el que se advierte algo inaceptable en el propio texto (78). Cuando Gusmán publica la reescritura de En el corazón de junio la encabeza con una « Nota de autor » en la que explicita las razones de su cambio. Gusmán señala haber seguido cuatro «coordenadas » para su corrección: suprime la abundancia de citas, trabaja sobre la referencialidad, reordena para lograr una mayor linealidad, administra la historia para contribuir con la verosimilitud. Dice Gusmán: « La anomia de determinada época histórica en que transcurre la acción creaba por sí misma un efecto de dispersión al que no había que sumarle 'una fragmentación estética' que podía resultar artificial» (10). Bajo esta mirada en la que se equipara contexto político y ficcionalidad, lo hermético como un programa estético deja de ser la condición de posibilidad de la ficción y aparece en cambio recuperado como falla. La fragmentación como principio constitutivo, la intertextualidad excesiva, la referencialidad elusiva de las que deriva un cierto efecto de lectura son consideradas a la distancia por Gusmán como una marca que hace evidente el artificio y que resulta innecesaria en el contexto de los 90 . Si nos detenemos a evaluar las diferencias entre ambas versiones de En el corazón de junio, vemos que casi todas son menores: se agregan nombres, se distinguen narradores, se precisa la topografía, se hilan fragmentos para dotar de mayor sentido a la historia. La modificación más drástica se hace en «Darkness", capítulo que se "despolitiza »: todo aquello inquietante presente en la primera edición en la segunda se borra o se explica: los cuerpos quebrados se transforman en maniquíes, la violencia se vincula con la ilegalidad del contrabando y la mención a los cuerpos narcotizados que se arrojan al río es sacada. Ese fragmento, el más evidente de la novela en su referencialidad, se envía en la segunda edición a la serie « En videncia ", sumando una nueva mediación, y se lo coloca así en el orden de lo imaginario, en el dominio de la alucinación.

Si con El frasquito la elección de Gusmán por una prosa hermética se inserta en disputas vigentes hacia dentro del campo literario de los 70, en cambio, con En el corazón de junio lo hermético paradójicamente subvierte su signo y aparece como la única forma posible de decir lo indecible. El ejercicio de una violencia política que atraviesa y rompe los cuerpos en el relato se proyecta sobre la escritura: la fragmentariedad de esos muchos seres desmembrados, desollados, desaparecidos se duplica en un modo de construcción de lo 
ficcional que rompe también con las pautas de construcción del verosímil realista. La reescritura en el 99 de En el corazón de junio es la reafirmación del viraje estético que se produce con Villa en tanto la apelación a una prosa hermética deja de ser una herramienta eficaz para construir sentidos en torno de la violencia política y se reduce a una falla que solo aporta artificialidad y confusión en un panorama que parece exigir otra configuración para el texto literario.

\section{BIBLIOGRAPHY}

Balderston, Daniel. « El significado latente en Respiración artificial de Ricardo Piglia y en El corazón de junio de Luis Gusmán » en V. V. A. A. Ficción y política. La narrativa argentina durante el proceso militar. Buenos Aires: Alianza/University of Minnesota, 1987.

Burucúa, José Emilio y Nicolás Kwiatkowski. Cómo sucedieron estas cosas. Representar masacres y genocidios. Buenos Aires: Katz, 2014.

Calloni, Stella. Operación Cóndor: pacto criminal. La Habana: Ed. Ciencias Sociales, 2006.

De Diego, José Luis. ¿Quién de nosotros escribirá el Facundo? Intelectuales y escritores en Argentina (1970-1986). La Plata: Al margen, 2001.

Gamerro, Carlos. « Introducción. El Ulises de Joyce » en Ulises. Claves de lectura. Buenos Aires: Norma, 2008.

García, Germán. Nanina. Buenos Aires: Jorge Álvarez, 1968.

Gilman, Claudia. Entre la pluma y el fusil. Debates y dilemas del escritor revolucionario en América Latina . Buenos Aires: Siglo XXI, 2003.

Giordano, Alberto. «Literal y El frasquito: las contradicciones de la vanguardia » en Revista de Lengua y Literatura. Neuquén: Universidad Nacional del Comahue, n 17-22, 1997.

Gramuglio, María Teresa. « Tres novelas argentinas » en Punto de vista. Buenos Aires: n 13, 1981. Gusmán, Luis. El frasquito. Buenos Aires: Noé, 1973.

. «El hombre de los gansos » en Revista Sitio. Buenos Aires, ㄲo 1, 1981.

. En el corazón de junio. Buenos Aires: Sudamericana, 1983.

. En el corazón de junio. Buenos Aires: Norma, 1999. Segunda edición revisada.

. « El derecho a la muerte escrita » en Epitafios. El derecho a la muerte escrita. Buenos Aires: Norma, 2005.

. Villa. Buenos Aires: Alfaguara, 1995.

. Ni muerto has perdido tu nombre. Buenos Aires: Sudamericana, 2002.

Idez, Ariel. Literal. La vanguardia intrigante. Buenos Aires: Prometeo, 2010.

Jitrik, Noé. «La operación de la escritura. El concepto central de corrección » en Los grados de la escritura. Buenos Aires: Manantial, 2000. 
Lamborghini, Osvaldo. El fiord. Buenos Aires: Chinatown, 1969.

Libertella, Héctor (comp). Literal 1973-1977. Buenos Aires: Santiago Arcos, 2002.

Martorell, Francisco. Operación Cóndor. El vuelo de la muerte. Santiago de Chile: LOM, 1999.

Monteleone, Jorge. « Sobre En el corazón de junio » en Sitio. Buenos Aires: n 3, agosto de 1983.

Novaro, Marcos y Vicente Palermo. La dictadura militar argentina. 1976/1983. Del golpe de Estado a la restauración democrática. Buenos Aires: Paidós, 2007.

Peller, Diego. « Ficciones teóricas en Literal » en Pasiones teóricas. Crítica y literatura en los setenta. Buenos Aires: Santiago Arcos, 2016.

Saer, Juan José. « Narrathon » (1973) en El concepto de ficción. Buenos Aires: Seix Barral, 2014.

Sarlo, Beatriz. « Literatura y política » en Punto de vista. Buenos Aires, no 19, 1983.

Strauss, Leo. « Escribir entre líneas, un arte olvidado » en Revista Sitio. Buenos Aires, no 1, 1981.

V. V. A. A. Escrito por los otros. Ensayos sobre los libros de Luis Gusmán. Buenos Aires: Norma, 2004.

\section{NOTES}

1. Página 122 de la primera edición.

2. En 2002 se publica una antología de Literal preparada por Héctor Libertella. La cita corresponde al manifiesto « No matar la palabra, no dejarse matar por ella » (1973) incluido en esa edición en la página 23. En 2011, la Biblioteca Nacional de Argentina edita el facsímil de los tres volúmenes de la revista que se editan originariamente en noviembre del $1973\left(n^{\circ} 1\right)$, mayo de $1975\left(n^{\circ} 2 / 3\right)$ y noviembre de 1977 ( $\left.n^{\circ} 4 / 5\right)$. Todas las citas que tomamos de Literal corresponden a la edición de Libertella.

3. Durante los 60 y 70, América Latina es atravesada por el impulso que la revolución cubana, la descolonización de África y la resistencia en Vietnam imprimen a la causa de liberación nacional: la década del 60 marca la emergencia de los primeros focos guerrilleros que optan por la lucha armada. Los principales grupos de orientación marxista que se constituyen en la región son el Frente Sandinista de Liberación Nacional (Nicaragua, 1961), el Movimiento de Izquierda Revolucionaria (Perú, 1962) y el Ejército de Liberación Nacional-Perú (1962), el Frente de Liberación Nacional Tupamaros (Uruguay, 1965), el Movimiento de Izquierda Revolucionaria-MIR (Chile, 1965), las Fuerzas Armadas Revolucionarias de Colombia-FARC (1966), el Ejército Revolucionario del Pueblo-ERP (Argentina, 1970). En Argentina surgen también grupos guerrilleros de orientación peronista: Uturuncos (1959), Acción Revolucionaria Peronista (1963), los Comandos Camilo Torres y un conjunto de agrupaciones que dará origen en 1970 a Montoneros. Como contrapartida, desde principios de los 70 se produce una serie de golpes de Estado en la región con los que se materializa el proyecto represivo que, en el caso del cono sur, se articula en la coordinación entre los mandos militares de, entre otros, Argentina, Bolivia, Brasil, Chile, Paraguay y Uruguay para llevar adelante diversas acciones represivas en el marco del Plan Cóndor. Para una descripción documentada y detallada que permite reconstruir el clima político e intelectual de los 60 y 70 en Latinoamérica cfr. la insoslayable investigación de Claudia Gilman, Entre la pluma y el fusil. Para un acercamiento a los pormenores del Plan Cóndor cfr. Stella Calloni Operación Cóndor: pacto criminal y Francisco Martorell Operación Cóndor. El vuelo de la muerte.

4. El armado en 1973 de la « Alianza Anticomunista Argentina » (la « Triple A ») marca la creación -con la venia del Estado- de una fuerza parapolicial integrada por sectores de la derecha peronista, la Policía y el Ejército que inicia el proceso represivo contra sectores de izquierda, proceso que continúa bajo el mando del Ministro López Rega y que se intensifica a partir del 
golpe de Estado del 76. Para un abordaje de estas cuestiones cfr. Marcos Novaro y Vicente Palermo La dictadura militar argentina. 1976/1983. Del golpe de Estado a la restauración democrática 5. Como se señala al inicio, no es la intención de este trabajo dar un panorama del entramado intelectual del que forma parte Gusmán, sino más bien recuperar aquellos postulados significativos para entender la parte de su obra cuyo análisis nos ocupa. Cfr. José Luis de Diego, ¿Quién de nosotros escribirá el Facundo? para un completo trabajo de análisis de los rasgos salientes de los campos cultural, literario e intelectual argentinos entre 1970 y 1986 a partir de un pormenorizado estudio de la narrativa, los debates intelectuales de la época, las publicaciones periódicas, las polémicas en torno del exilio y los modos de concebir las funciones del intelectual. Para una perspectiva que indaga «la pulsión teórica» en la literatura, la crítica y las publicaciones del período cfr. Diego Peller, Pasiones teóricas. Crítica y literatura en los setenta, en especial el capítulo « Ficciones teóricas en Literal ».

6. Para un estudio contemporáneo de los rasgos de la narrativa publicada durante el Proceso militar cfr. María Teresa Gramuglio «Tres novelas argentinas" (1981), y Beatriz Sarlo « Literatura y política » (1983).

7. Gusmán comienza a escribir algunos de los fragmentos que compondrán la novela hacia finales de los 70. Por ejemplo, bajo el título «El hombre de los gansos » publica una versión de lo que será el primer capítulo de la novela en el número 1 de la revista Sitio durante 1981.

8. Cfr. Daniel Balderston «El significado latente en Respiración artificial de Ricardo Piglia y En el corazón de junio de Luis Gusmán ».

9. Una articulación de ese distanciamiento cobra cuerpo en la sustitución en 1984 del prólogo de Piglia a El frasquito. Al respecto sostiene Alberto Giordano: « cuando Gusmán piense su literatura desde una perspectiva diversa a la del vanguardismo, cuando ya no se identifique con la 'idea intencional de literatura transgresiva' decidirá suprimir el prólogo de Piglia y acompañar la reedición de El frasquito con un prólogo propio en el que dejará constancia de su descreimiento en 'una literatura maldita que encuentra su razón de ser en la intencionalidad' » (141).

10. Gusmán comparte directorio junto con Ramón Alcalde, Eduardo Grüner, Jorge Jinkins, Mario Levin y Luis Thonis. Entre 1981 y 1987 se editan los 7 números de Sitio.

11. El 16 de junio de 1955 varios escuadrones de la aviación naval argentina encabezan un intento de golpe de Estado contra el presidente Juan Domingo Perón bombardeando Plaza de Mayo y la sede de la Casa de Gobierno. En el episodio que tristemente constituye el bautismo de fuego de la aviación naval mueren 308 personas y más de 700 resultan heridas. Si bien estas son las muertes documentadas se cree que el número de víctimas podría ser mayor.

\section{ABSTRACTS}

This paper analyses En el corazón de junio (1983), by Luis Gusmán to explore his literary procedures to figure state violence. The book is published in the last year of the argentinian last military dictatorship (1976-1983), so Gusmán tries to do an hermetic prose to avoid censorship but capable to symbolize the violence over the words and the bodies. The narration of violence appears in the novel through paired figures: the obliterated and the expressed, the inscription and the erasure, the hermetic and their interpretation. Twenty years later, Gusmán rewrites his novel to frame the text into realism paradigma. The modulations between both versions allow to study the features that caracterize his poetics in diferent historic periods with distinct conceptions about recent past. 
En este artículo se analiza la novela En el corazón de junio (1983), de Luis Gusmán con el objetivo de estudiar los procedimientos a través de los que se figura la violencia de Estado. Publicada durante el último año de la última dictadura militar argentina (1976-1983), la novela de Gusmán apuesta a la construcción de una prosa hermética capaz de mostrar en su revés las huellas de la violencia sobre los cuerpos y sobre las palabras. La potencia de En el corazón de junio para narrar la violencia se trama en la presentación de figuras pareadas que se tensionan y se superponen: lo elidido y lo dicho, la inscripción y el borramiento, lo hermético y su interpretación. Veinte años después de la primera edición, Gusmán reescribe su novela para acercarla a los lineamientos generales de la estética del realismo. El análisis de los rasgos de cada versión permite estudiar las variaciones de una poética de autor que se desdobla y apuesta por la creación de efectos de lectura en contextos en los que el terrorismo de Estado y sus consecuencias tienen interpretaciones distintas.

Dans cet article on analise le roman En el corazón de junio (1983), de Luis Gusmán, dans le but d'étudier les procédures littéraires par lesquelles se représente la violence d'Etat. Publié au cours de la la dernière année de la dernière dictature militaire en Argentine (1976-1983), le roman de Gusmán mise sur la construction d'une prose hermétique capable de montrer dans son revers des traces de la violence sur les corps et les mots. La puissance de En el corazón de junio à raconter la violence se trame à travers la présentation de figures doubles qui s'opossent et se chevauchent: l'élision et ce qui a été dit, l'inscription et l'effacement, l'hermétique et l'interprétation. Vingt ans après la première édition, Gusman réécrit son roman pour l'amener aux orientations générales de l'esthétique du réalisme. L'analyse des caractéristiques de chaque version permet d'étudier les variations d'une poétique d'autor qui comporte une double conception et qui mise sur la création d'effets de lecture dans des contextes où le terrorisme d'État et ses conséquences ont des interprétations différentes.

\section{INDEX}

Palabras claves: narrativa argentina, Luis Gusmán, violencia de Estado, hermetismo

Mots-clés: narrative argentine, Luis Gusmán, violence d'Etat, hermetisme

Keywords: argentinian narrative, Luis Gusmán, state violence, hermetisme

\section{AUTHOR}

\section{ANDREA COBAS CARRAL}

Universidad de Buenos Aires, Facultad de Filosofía y Letras

Docente e investigadora

acobascarral@filo.uba.ar 